\title{
CROSS-CULTURAL COMPARISON BETWEEN ARABIC AND WESTERN COUNTRIES IN LOCATION-BASED SOCIAL NETWORKING USAGE ON MOBILE PHONES: THE CASE OF FACEBOOK
}

\author{
Soumaya Frigui, University of Bologna, soumaya.frigui2@unibo.it \\ Kamel Rouibah, College of Business Administration, Kuwait University,krouibah@cba.edu.kw \\ Gian Luca Marzocchi, University of Bologna, gialuca.marzocchi@unibo.it
}

\begin{abstract}
Day after day, location based social networking (LBSN) services are becoming increasingly more popular and rapidly adopted on a global scale by attracting millions of users. Many of LBSN users have integrated these services into their daily practices. Furthermore, mobile LBSN adoption and use differs greatly across national contexts and the impact of cultural factors on the LBSN use is considered as an interesting issue to be addressed. Therefore, this research in progress proposes a new concept model for mobile LBSN adoption and usage that is based on three models: Triandis's Model, the Technology Acceptance Model (TAM), and Hofstede's cultural model. This proposed research model explores the structural relationships among mobile LBSN actual usage on mobile phones and the LBSN enablers: perceived enjoyment, facilitating conditions, and social factors. Further, the relationships between the proposed research model' constructs are moderated by Hofstede's cultural dimensions. It also discusses how this research model will be tested across two different cultures (Western vs. Non Western) in different nations (Tunisia, Morocco, Kuwait, and Italy). It is expected that this comparative study will contribute to efforts of identifying the role of contextual cultural factors in macro-level LBSN adoption and diffusion on mobile phones and will have potential benefits to advance research and practice of social networking services (SNSS) and LBS.
\end{abstract}

Keywords: Location Based Social Networking (LBSN), Mobile Phones, Cross-Cultural Comparison, Triandis's Model and Facebook.

\section{INTRODUCTION}

Location based social networking (LBSN) has a crucial role as part of networks, and as a result, these services cannot be used isolated from other potential patterns of use. Kraemer et al. [45] argued that variations in innovation outcomes in different countries are even greater if the innovation is a consumer technology. Thus, it can be assumed that LBSN adoption and use differs greatly across national contexts and the effect of cultural factors on the LBSN use is considered as an interesting issue to be addressed. In other words, since the ubiquitous nature of the Internet is facilitating LBSN activities on mobile phones across nations, thus, a cross-cultural approach to research on attitudes and adoption of LBSN is both justified and necessary. Indeed, these activities demand a new conceptualization of LBSN users behaviour that transcends national boundaries and takes into consideration cross-cultural effects. Furthermore, Kim et al. [44] provide a concise summary of the extant literature, and find evidence for significant variations between countries in adoption rates and usage patterns of IT applications.

To better understand what drives LBSN across cultures, this paper aims, first, to outline national differences in LBSN use patterns and second, to add validation to technology acceptance theories and models from a cultural perspective to capture behavioural adoption and usage of LBSN on mobile phones in different dissimilar countries: Tunisia, Morocco, Kuwait and Italy. In order to enhance our understanding on the cultural effect, we draw upon the work of Hofstede [32] and use his measures of cultural dimensions to examine the link between cultural context and LBSN adoption and use on mobile phones.

Despite this breadth of research on behavioural use of LBSN, larger scale research is still needed to reach significant results in area of evaluating cross-cultural issues in social networking services across the world [25]. Accordingly, the question of how culture might moderate LBSN' users behaviour remains largely unanswered. Therefore, technology acceptance theories and models need additional validation from a cultural perspective. 
In order to address these gaps in the literature, we aim to answer the following issues:

RQ1. Does culture play a significant role on the adoption and usage of LBSN on mobile phones across different cultural contexts (Arabic and Western cultures)? If so, RQ2. To what extend do Hofstede's cultural dimensions impact the LBSN adoption across these cultures?

\section{RESEARCH BACKGROUND AND THEORETICAL FRAMEWORK}

This section will briefly describe the main literature streams that are relevant for this study.

\section{Theoretical models of technology acceptance and adoption}

Many competing theoretical models co-exist in the technology acceptance and adoption literature, each with different focus and tested in different contexts (e.g. E-commerce, E-learning, Social Networking, Internet Usage, etc.). For the purposes of this study, we focus on previous results based on the technology acceptance model (TAM) and the Triandis's model in the innovative technology context.

Technology Acceptance Model (TAM). The TAM suggests that users formulate a positive attitude toward the technology when they perceive it to be useful and easy to use. Furthermore, user adoption and usage of a new information system can also be determined by the beliefs and attitudes toward the information systems [20]. In this sense, prior researches [36, 42] used TAM to investigate the acceptance and the intention to use of Information Technology (IT).

Despite the wide use of TAM by researchers and practitioners to predict and explain user acceptance of IT, researchers have also recognized that the generality of TAM fails to supply more meaningful information on user's opinions about a specific system [50].

Further, Dillon et al.[23] argued the major theoretical limitation of TAM is the "exclusion of the possibility of influence from institutional, social, and personal control factors". Therefore, some authors provided a refined view to assess the appropriateness of the model for predicting general individual acceptance, since the main TAM constructs do not fully reflect the specific influences of technological and usage-context factors that may alter user acceptance [43].

Triandis's Theory of Interpersonal Behaviour (TIB). The TIB is considered as a theory of social behaviour that complements the Theory of Reasoned Action (TRA) and provides the norms through which human social behaviour can be understood [71]. Triandis's model argued the probability of performing a given behaviour is determined by a number of factors and considers habit, social factors (similar to subjective norms), affect, perceived consequences, and facilitating conditions (similar to perceived behavioural control) for understanding human behaviour of intention and actual behaviour.

In this study, we focus on a subset of Triandis's framework which is similar to the one adopted in Thompson et al. [74], and W. Chueng et al. [16], because it is relevant to this study.

\section{Related work to Location-Based Social Networking (LBSN)}

What are LBSN? The LBSN phenomenon has also been named Locative Mobile Social Networks. De Souza et al.[21] defined LBSN as commercial applications, available through a cell phone, that help build networks of mobile nodes (in this case moving people) by displaying the geographic position of users on a map. Users are enabled to locate each other in physical space and interact with one another depending on the relative distance. Furthermore, Fusco et al.[29] defined LBSN "as the converge between location-based services (LBS) and online social networking (OSN)". Further, they argued that LBSN applications offer users the ability to look up the location of another "friend" remotely using a smart phone, desktop or other device any time anywhere. For the purpose of our study, we adopt the LBSN definition of Fusco et al. [29].

Moreover, $\mathrm{Lu}$ et al.[51] argued that LBSN are becoming increasingly popular on a global scale. Further, they deemed that full bloom of LBS depends not only on technology improvement and development but as well as user acceptance. 


\section{Issues in Information Systems \\ Volume 14, Issue 2, pp.109-118, 2013}

Why LBSN? LBSN allows users to interact relative to their current locations, for instance, to match users with a place, event or local group to socialize in or facilitate users' decision on a meeting activity within the users group. Popular LBSN applications like Foursquare, Facebook, and Gowalla use LBS capabilities via mobile device Internet connection to let users notify others of their locations by "checking in" to that location. Such social networking sites (SNSs) since the moment of their introduction have attracted millions of users, many of whom have integrated these sites into their daily practices [10]. In this sense, Chow et al. [18] argued that social networking applications have become one of the most important web services (e.g., Facebook and Twitter), which provide Internet-based platforms for users to interact with other people that are socially relevant to them (e.g., their friends). In the last years, the growth of Facebook' users number affirms that LBS are becoming more popular, rapidly adopted, and incorporated systems such as social networking sites that are already extensively. In this sense, statistics made by Shields (2010) reported that Facebook has confirmed that more than 150 million people "actively" use Facebook on their mobile device.

Research into social networking usage patterns in the social relationship context suggests that Facebook is used and adopted primarily to maintain contact with offline connections rather than to develop new relationships [26]. In this sense, Lampe et al. [46] found that Facebook is used by students for purposes related to "social searching" rather than for "social browsing". Accordingly, these studies indicate that Facebook serves a "sociability function" that enables users to maintain relationships with offline connections both near and far.

In addition to the research on the social ties of social networking usage, researches focused on the privacy issue of LBSN usage on mobile phones. Ajami et al. [3] addressed the privacy issues in mobile social networking applications considering the users' points-of-view and their acceptance of such applications. Further, they elucidated some of the suggested mechanisms to endorse users' trust in social interactions.

\section{Culture perspective}

Leung et al. [49] argued "the view that social behaviour is partly a product of dominant values and ideologies of a culture has gained increasing acceptance in academic psychology". In earlier research, there have been enormous efforts to examine human cultures and their cultural differences in several fields such as anthropology and cross-cultural psychology $[1,32,66,67,76]$. In spite of this, Straub et al. [70] argued cross-cultural study has not received as much attention as necessary in IS research areas because of its difficulties in explicitly defining and measuring the concept of culture. Further, Rouibah [65] argued very few studies have focused on IT/ICT in the Arab world compared to those in North America and Europe. Therefore, this study attempts to investigate the influence of the Arabic culture comparing to the Western culture on the LBSN usage on mobile phones.

Hofstede's cultural dimensions. Hofstede [34] defines culture as patterns of thinking, feeling and potential acting, which have been learned throughout a lifetime, and which are likely to be used repeatedly and unlikely (or difficult) to be changed by the individual.

Hofstede [34] describes culture using five dimensions: Power Distance (PDI), Uncertainty Avoidance (UAI), Individualism vs. Collectivism, Long-Term Orientation (LTO), and Masculinity (MAS).

Regardless of the considerable criticism of Hofstede's work over the years [55, 76], Hofstede's framework had a widespread use in social science research for defining and measuring cultural differences [68], and it has also received strong empirical support [69]. Despite, Hofstede's cultural dimensions were provided as the most influential culture theory among social science research [57], there are still few studies [12, 78, 82] focusing on the exploitation and application of such cultural dimensions in explaining LBSN behaviour usage across-cultures.

Characteristics of Arab culture. Arab culture puts an emphasis on social relationships, is based on oral communication, and has its priority on face-to-face interactions. With the emergence of new ICT, Arab people found new channels to disguise their real identity, to talk free of any social norm [65]. These characteristics may explain why and how Arabs engage in social network sites in general and LBSN in particular, especially after the critical roles of SNSs in so-called Arab Spring [6].

Characteristics of Western culture. Western culture is characterized by the freedom of speech and freedom of association-the values of classical democracy [50]. Further, it puts an emphasis on the individual person who is 
independent and self-reliant. In this sense, individuals, in the Western culture, should be able to act on their own reason without interference from others. Yong [81] argued westerners tend to think more analytically, as befits their philosophical heritage of reductionism, utilitarianism and so on.

\section{CONCEPTUAL DEVELOPMENT}

LBSN usage on mobile phones are currently considered as young phenomenon in growth, we believe social pressure plays an important role in explaining their use from a social relationship perspective. Further, the facilitating conditions (such as the availability of internet connection on the mobile phone, screen dimension etc.) are considered also an important element in analysing such phenomenon. For these reasons, we decided to adopt a more comprehensive social psychological model, the Triandis's model [75], which includes both the social factors and facilitating conditions constructs, to explain LBSN usage on mobile phones in this study. However, in our research, we applied the Triandis's model to predict LBSN actual usage on mobile phones for social relationship context. The direct effects of facilitating conditions, social factors, affect, and attitude on actual behaviour (LBSN usage on mobile phones) are investigated in this study. Since we were interested in the prediction of actual behaviour, "intention" was excluded from the research model similar to the work of W. Chueng et al [16], Kim and Lee [71] and Bergeron et al [9]. Instead, we studied the direct effects of social factors, affect, and attitude on current behaviour. Often habit is assessed by using a measurement of past behaviour or behavioural frequency [15], as is the case with the Triandis's model. In our investigation the construct "Habit" was also dropped from our research model because in a crosssectional study measurements for habit and actual behaviour are the same. For the same reasons, some prior studies applied the Triandis's model and were interested in the prediction of actual behaviour excluded "habit" construct $[14,16,74]$.

Furthermore, the Triandis's model has been successfully used in a number of technology adoption studies $[9,71,16]$. However, certain important relationships were neither included nor tested using this model. Nevertheless, these relationships, such as how cultural dimensions affect the LBSN adoption and usage on mobile phones. Therefore, we attempt to incorporate Hofstede's cultural dimensions into the Triandis's model to form a new research framework for the investigation of factors affecting the use of LBSN on mobile phones and to contribute to the LBSN literature. The results may prove insightful also for telecommunication operators hoping to encourage more use of these social networking services on the mobile phones.

Summing up, we developed our research model and hypotheses (Figure 2) by modifying and combining some relevant constructs for the research from TAM and the TIB to enhance our understanding of the determinants and the antecedents of LBSN usage on mobile phones across Western and Arabic cultures. Accordingly, based on previous results of Pavlou and Chai [58] study, we incorporate three of Hofstede's [34] cultural dimensions: individualism vs. collectivism (IND), high vs. low power distance (DPI), and long vs. short orientation term (LOT), into the research model as key moderators of the model' constructs, aiming to explain LBSN use on mobile phones across cultures. 


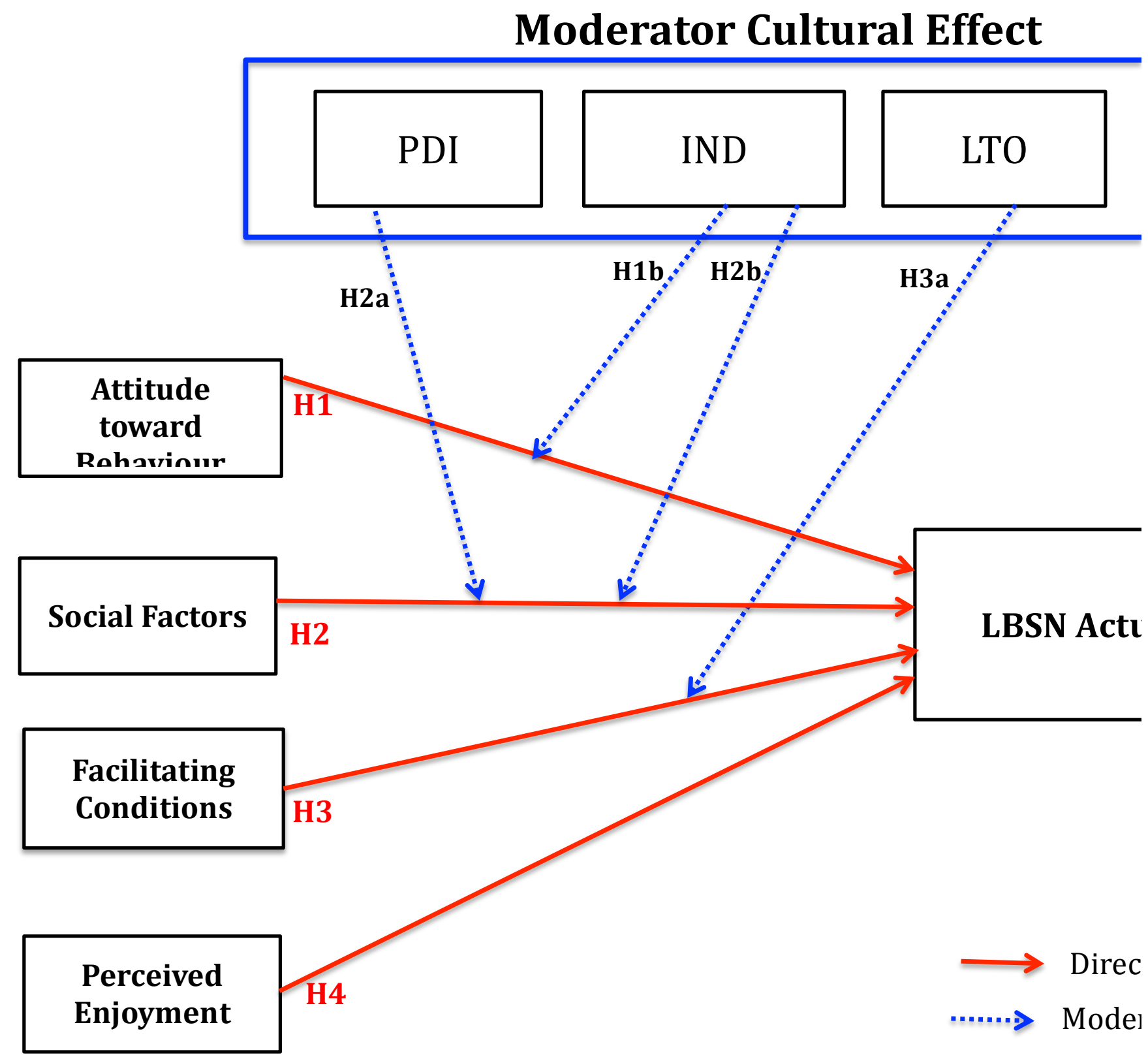

Figure 2. Proposed Research Model and Hypotheses

Hypotheses

\subsection{Direct Effect}

Attitude. Attitude towards behaviour "is a person's inclination to exhibit a certain response toward a concept or object" [24].

Further, attitude toward an innovation is a critical intervening variable in the innovation adoption decision [64]. Thus, attitude toward a specific information technology is conceptualized as a potential user's assessment of the desirability of using that technology $[20,60]$ and, according to the TAM, predicts an individual's use of technology. Therefore, we would expect that:

H1. There is a positive relationship between an individual's attitude toward LBSN and his/her actual use of LBSN on mobile phones. 
Social Factors. Social factor is defined as "an individual's internalization of the reference group's subjective culture, and specific interpersonal agreements that the individual has made with others, in specific social situations" [75]. In other words, LBSN' users may believe that their family, colleagues and peers would approve certain LBSN behaviours, and this belief plays an important role in influencing their behaviour.

Further, when the Triandis's model [75] was used as a guiding framework, a number of studies found a positive relationship between what the subject thought others wanted him/her to do and the usage of various IS $[9,30]$. Therefore, consistent with previous empirical findings based on Triandis's model, we would predict that:

H2: There is a positive relationship between the social factor and the actual LBSN usage on mobile phones.

Facilitating Conditions. Facilitating conditions are the 'objective factors, 'out there', in the environment, that several judges or observers can agree make an act easy to do [75]. This construct is related to the perceived behavioural controls concept in the TPB [59]. Triandis [75] explains that an objective environmental condition can function as an important variable that prevents the behaviour from occurring, even despite a strong intention to engage in the behaviour. Therefore, we predict that:

H3: There is a positive relationship between facilitating conditions and the actual LBSN usage on mobile phones.

Perceived enjoyment. Perceived enjoyment may be defined as the extent to which the activity of using the computer is perceived to be enjoyable in its own right, apart from any performance consequences that may be anticipated $[13,22,53]$. Hence, individuals who experience immediate pleasure and joy from using the computer per se will be more likely to use it more extensively than others [73]. By extending these results to the context of LBSN, we can therefore, postulate that:

H4: There is a positive relationship between perceived enjoyment and the actual LBSN usage on mobile phones.

\subsection{Moderator Effect}

Power Distance (PDI). With respect to social factors, the first relevant cultural difference between Arabic nations (Tunisia, Morocco, and Kuwait) and Western nations (Italy) is power distance (PDI) dimension, which refers to the extent that people accept a hierarchical system with an unequal power distribution [32]. High power distance means that less powerful individuals accept large status differences. Superiors tend to be autocratic and paternalistic, and subordinates willingly do as they are told [33]. Therefore, we can postulate that:

H2a: The positive relationship between social factors and the actual LBSN usage on mobile phones is stronger in nations with high level of power distance.

Individualism vs. Collectivism. In addition to (PDI), we note a second important cultural difference related to social factors between Arabic nations and Western nations: individualism vs. collectivism. Members of individualistic societies prefer self-sufficiency, while those in collectivistic cultures acknowledge their interdependent natures and obligations to the group [32]. Previous studies have replicated Hofstede's cultural dimension of collectivism, finding that it places relatively greater importance on the group's needs and norms than individualism [76]. Because Arabic nations are highly collectivist and Western nations are highly individualistic, we expect a cultural difference in the effect of social factors on the actual LBSN usage on mobile phones. Therefore, we postulate:

H2b: The positive relationship between social factors and the actual LBSN usage on mobile phones is stronger in collectivist than in individualist nations.

Further, we can note that the cultural component is relevant to the relationship between attitude toward LBSN on mobile phones and actual usage. Collectivist nations (e.g. Tunisia, Morocco, and Kuwait) have strong relations within the "in-group", in other words, peers, the extended family and familiar acquaintances 
have a key role in impacting the individual's behaviour [35]. In-group relations focus on maintaining harmony by going along with the group's wishes and promoting long-term relationships. Therefore, Hofstede's cultural dimension of individualism vs. collectivism has also an impact on the attitude toward using LBSN on mobile phones with the actual behaviour, thus, we expect that:

H1b: The positive relationship between attitude and the actual LBSN usage on mobile phones is stronger in collectivist than in individualist nations.

Long-Term Orientation (LTO). Cultural differences between Arabic and Western nations are also relevant to the relationship between the facilitating conditions and the actual behaviour. According to Hofstede [34], Arabic countries are extremely high on long-term orientation which is a cultural dimension reminiscent of the teachings of Confucius. In essence, this gives such people more control over their actions. In contrast to Arabic countries, Western countries in particular, Italy has low scores on long-term orientation dimension. For this reason, we would expect Arabic users to require more control of their LBSN use on mobile phones than Italian users, and rely on this control in their LBSN adoption behaviour.

H3a: The positive relationship between facilitating conditions and the actual LBSN usage on mobile phones is stronger in nations characterized by long versus short-term orientation.

\section{RESEARCH METHODOLOGY}

\section{Research context}

The research setting we would like to investigate is the LBSN usage on mobile phones in the social context across different cultures. The proliferation of LBSN provides the ubiquity, convenience, localization, and personalization for users participating in mobile communications and service activities. Therefore, it is required to any LBSN providers, in order to respond to critical issue in social networking sites around the world, to pay attention to how they fit their social networking services to the differences across-culture and not putting their efforts just on language translation and other visible aspects when entering a foreign market. Indeed, LBSN has a ubiquitous nature, hence, a cross-cultural approach to research on adoption and usage of LBSN is essential.

Kuwait, Tunisia, Morocco, and Italy are chosen for this study because they represent areas with apparently analogous information communication technology infrastructures but with nearly reverse positions on three important Hofstede's cultural dimensions.

2. Research design

A survey methodology will be used for this study. A questionnaire will be developed, tested and administered to each sample of these four populations.

Moreover, Structural Equation Modelling (SEM) could be used as the main statistical technique. In addition, Confirmatory factor analysis will be performed to examine the reliability and validity of the measurement model.

Sample. Samples will be drawn from Kuwaiti, Tunisian, Moroccan, and Italian' undergraduate university students. The present research will use a matched samples technique which is considered as a good approach advocated by cross-cultural research methodologists, where the samples of cultural groups to be compared are made as similar as possible in their demographic characteristics [79].

Questionnaires. Questionnaires will be developed in English, Italian, and Arabic based on the research model and an exhaustive literature review. Furthermore, the questionnaires' items will be taken from existing studies on the use of Triandis's model [75] applied to IT use [16] and on the use of TAM [60]. Finally, we will use the CVSCALE [82], which is a psychometric measurement tool that assesses Hofstede's cultural dimensions. However, questionnaires will be adapted to fit LBSN users behaviour.

Pre-test. A pre-test will be performed and tested on several undergraduate students who are familiar with Facebook application on mobile phone. Actually, the main purpose of the pre-test is to measure and validate the feasibility of the questionnaire and also obtain some qualitative feedback. Based on this feedback, adjustments will be made to the proposed model accordingly. 
Pilot test. A pilot test of the questionnaire will be conducted on a convenience sample of mobile LBSN' users (Undergraduate students) and adequate modification will be made to the questionnaire's structure (form and wording and phrasing of some questions) if it is necessary.

\section{CONCLUSIONS}

From a theoretical point of view, the comparative analyse presented in this work in progress will contribute to efforts of identifying the role of contextual factors in individual-level adoption and diffusion processes of LBSN on mobile phones. Further, this study places an emphasis on theory and aims at additional validation of the Triandis's model, attempting to integrate Hofstede's cultural dimensions into the model. Thus, it enlarges the picture of the relationship of LBSN and culture, still restricted in recent research.

For practices, the study suggests that investigating the LBSN users adoption on mobile phones over time with attention to the effect Hofstede's cultural dimensions at users behaviour are appropriate starting points when dealing with cultural diversity in LBSN environments.

In our days, LBSN providers and practitioners need to acquire a deeper understanding of the impact of users characteristics and their behaviour on the LBSN usage on mobile phones in different cultural contexts. Therefore, the proposed research model will give LBSN' providers insights to predict user's willingness to accept and use LBSN on mobile phones, and finally to develop corrective steps.

\section{REFERENCES}

[1] Abramson, P. R., and Inglehart, R. (1995). Value change in global perspective. Ann Arbor: University of Michigan.

[2] Adams, DA, Nelson, RR and Todd, PA (1992). Perceived usefulness, ease of use, and usage of information technology: A replication, MIS Quarterly, vol. 16, no. 2, pp. 227-47.

[3] Ajami, R., Al Qirim, N., and Ramadan, N., (2012). Privacy Issues in Mobile Social Networks. Procedia Computer Science, Vol. 10, pp: $672-679$.

[6] Al Omoush, K., Yaseen, S., and Alma'aitah M., (2012). The impact of Arab cultural values on online social networking: The case of Facebook. Computers in Human Behavior, Vol. 28, pp. 2387-2399.

[8] Armitage C. J., Conner M. (2001), "Efficacy of the Theory of Planned Behaviour: A meta- analytic review", British Journal of Social Psychology, Volume 40, Number 4, December 2001, pp. 471-499.

[9] Bergeron, F., Raymond, L., Rivard, S., and Gara, M., (1995). Determinants of EIS use: Testing a behavioral model. Decision Support Systems, Vol. 14, pp: 131-146.

[10] Boyd D., and Ellison N., (2008). Social network sites: Definition, history, and scholarship. Journal of Computer- Mediated Communication 13: 210-30.

[11] Boyd, D. M.; Ellison, N. B. 2008. Social Network Sites: Definition, History, and Scholarship, Journal of Computer-Mediated Communication 13(1): 210- 230.

[12] Cardon, P., Marshall, B., Norris, D. T., Cho, J., Choi, J., Cui, L., et al. (2009). Online and offline social ties of social network website users: An exploratory study in eleven societies. Journal of Computer Information Systems, 50(1), 54-64.

[13] Carroll, J.M. and Thomas, J.C. (1988), “Fun", SIGCHI Bulletin, Vol. 19, pp. 21-4.

[14] Chang, M.K., Cheung, W., Cheng, C.-H., \& Yeung, J.H.Y. (2008). Understanding ERP system adoption from the users' perspective. International Journal of Production Economics, 113(2), 928-942.

[15] Cheung, C.M.K., \& Limayem, M. (2005). Understanding continuance of advanced Internet-based

[16] Cheung, W., Chang, M., Lai, V., (2000). Prediction of Internet and World Wide Web usage at work: a test of an extended Triandis model. Decision Support Systems, Vol. 30, p: 83-100.

[18] Chow, C., Bao, J., and Mohamed F. Mokbel, (2010). Towards location-based social networking services. GIS-LBSN 2010: 31-38.

[19] Davis, C. E. (1996). Perceived security threats to today's accounting information systems: a survey of CISAs, IS Audit \& Control Journal, Vol. 3, pp. 38-41.

[20] Davis, FD, Bagozzi, RP \& Warshaw, PR (1989), User acceptance of computer-technology - a comparison of two theoretical-models, Management Science, vol. 35, no. 8, pp. 982-1003.

[21] De Souza e Silva A., and Frith J., (2010). Locative mobile social networks: Mapping communication and location in urban spaces. Mobilities 5: 485-505

[22] Deci, E.L., (1971). Effects of externally mediated rewards on intrinsic motivation. Journal of Personality and Social Psychology, Vol. 18, pp. 105-15. 


\section{Issues in Information Systems \\ Volume 14, Issue 2, pp.109-118, 2013}

[23] Dillon, A., and Morris, M., (1996). User acceptance of information technology: theories and models, Journal of American Society for Information Science, vol. 31, pp: 3-32.

[24] Doob, L. W., (1947). The behavior of attitudes. Psychological Review, Vol. 54, pp: 135-156.

[25] Elena Vitkauskaite (2010), Overview of research on cross-cultural impact on social networking sites, Economics and Management, ISSN 1822-6515.

[26] Ellison, N., Steinfield, C., \& Lampe, C. (2007). The benefits of Facebook "friends": Exploring the relationship between college students' use of online social networks and social capital. Journal of ComputerMediated Communication, 12(3).

[29] Fusco, S. J., K. Michael, et al. (2011). Monitoring People using Location-Based Social Networking and its Negative Impact on Trust: An Exploratory Contextual Analysis of Five Types of "Friend" Relationships. International Symposium on Technology and Society, Chicago, Illinois: 1-8.

[30] G. Pare, J. Elam, (1995). Discretionary use of personal computers by knowledge workers: testing of a social psychology theoreti- cal model, Behavior and Information Technology 14 4. P: 215-228.

[31] Grellhesl, M., and Punyanunt-Carter, N., (2012). Using the uses and gratifications theory to understand gratifications sought through text messaging practices of male and female undergraduate students. Computers in Human Behavior, Vol. 28, pp. 2175-2181.

[32] Hofstede, G. (1980). Culture's consequences: International differences in work-related values. Beverly Hills, Cal and London: Sage.

[33] Hofstede, G. (1991). Cultures and organizations: Software of the mind. London: Macmillan.

[34] Hofstede, G. (2001). Culture's consequences: Comparing values, behaviors, institutions, and organizations across nations. Thousand Oaks, CA: SAGE.

[35] Hofstede, G. and M. H. Bond (1988). The Confucius connection: From cultural roots to economic growth. Organizational Dynamics 16(4): 5-21.

[36] Hossain, L., and De Silva, A., (2009). Exploring user acceptance of technology using social networks. Journal of High Technology Management Research, Vol. 20, pp.1-18.

[37] Hsu, C., and Lin, J., (2008). Acceptance of blog usage: The roles of technology acceptance, social influence and knowledge sharing motivation. Information \& Management, Vol. 45, pp. 65-74.

[38] Hu, P., Clark, T., and Ma, W., (2003). Examining technology acceptance by school teachers: a longitudinal study. Information \& Management, Vol. 41, pp. 227-241.

[39] Igbaria, M., Iivari, J. and Maragahh, H. (1995), "Why do individuals use computer technology? A Finnish case study", Information and Management, Vol. 5, pp. 227-38.

[40] Jackson, J., Yi, M., and Park, J., (2013). An empirical test of three mediation models for the relationship between personal innovativeness and user acceptance of technology. Information \& Management, Vol. 50, pp.154-161.

[42] Kaba, B., and Osei-Bryson, K., (2013). Examining influence of national culture on individuals' attitude and use of information and communication technology: Assessment of moderating effect of culture through cross countries study. International Journal of Information Management, Vol. 33, pp. 441-452.

[43] Kamel Rouibah, (2008). Social Usage of Instant Messaging by individuals outside the workplace in Kuwait: A structural Equation Model.IT \& People.Vol. 21, No 1, pp. 34-68.

[44] Kim, J., Lee, I., Lee, Y. \& Choi, B. (2004). Exploring E-business Implications of the Mobile Internet: A Cross-national Survey of Hong Kong, Japan and Korea, International Journal of Mobile Communication, Vol. 2, No. 1:1-21.

[45] Kraemer, K. L., Dedrick, J., \& Melville, N. P. (2006). Globalization and national diversity: Ecommerce diffusion and impacts across nations. In K. L Kraemer, J. Dedrick, N. P. Melville, \& K. Zhu (Eds.), Global e-Commerce: Impacts of National Environment and Policy (pp. 13-61). Cambridge, UK: Cambridge University Press.

[46] Lampe, C., Ellison, N., \& Steinfield, C. (2006). A Face(book) in the crowd: Social searching vs.social browsing. Proceedings of CSCW-2006 (pp. 167-170). New York: ACM Press

[47] learning technologies: The role of satisfaction, prior behaviour, and habit, Proceedings of the Ninth Pacific Asia Conference on Information Systems (PACIS 2005), Bangkok, Thailand, 7-10.

[49] Leung, K., and M. Bond (1989). On the Empirical Identification of Dimensions for Cross-Cultural Comparisons. Journal of Cross-Cultural Psychology, 20: 133-51.

[50] Leoussi Athena (2000). IT in Western Culture: A New Technology with Ancient Roots. Knowledge Technology \& Policy | June 22, 2000.

[51] Lu, J., Yu, C.S., Liu, C., Yao, J., (2003). Technology acceptance model for wireless Internet. Journal of Internet Research 13 (2), 206-222.

[52] Madden, Thomas J., Pamela Scholder Ellen and Icek Ajzen (1992). A Comparison of the Theory of Planned Behavior and the Theory of Reasoned Action. Personality and Social Psychology Bulletin, 18 (1), 3B9.

[53] Malone, T.W. (1981), "Toward a theory of intrinsically motivating instruction", Cognitive Science, Vol. 4, pp. 333-69. 


\section{Issues in Information Systems \\ Volume 14, Issue 2, pp.109-118, 2013}

[54] Mathieson, K. (1991). Predicting user intentions: Comparing the technology acceptance model with the theory of planned behavior. Information Systems Research, 2(3), 173-191.

[55] McSweeney, B. (2002). Hofstede's Model of National Cultural Differences and their Consequences: A Triumph of Faith - a Failure of Analysis, Human Relations, Vol. 55, No. 1:89-118.

[57] Nakata, C. and K. Sivakumar (2001). Instituting the Marketing Concept in a Multinational Setting: The Role of National Culture, Journal of the Academy of Marketing Science, Vol. 29, No. 3:255-275.

[58] Pavlou, P., and Chai, L., (2002). WHAT DRIVES ELECTRONIC COMMERCE ACROSS CULTURES? A CROSS-CULTURAL EMPIRICAL INVESTIGATION OF THE THEORY OF PLANNED BEHAVIOR. Journal of Electronic Commerce Research, VOL. 3, NO. 4.

[59] Pee, L.G., Woon, I.M.Y., \& Kankanhalli, A. (2008). Explaining non-work-related computing in the workplace: A comparison of alternative models. Information \& Management, 45(2),pp:120-130.

[60] Porter, C., E., and Donthu, N., (2006). Using the technology acceptance model to explain how attitudes determine Internet usage: The role of perceived access barriers and demographics. Journal of Business Research, Vol.59, pp: 999-1007.

[61] R. R. Dholakia and N. Dholakia, Mobility and markets: emerging outlines for m-commerce, Journal of Business Research, vol. 57, no. 12, pp. 1391-1396, 2004.

[64] Rogers, E. M. (1995). Diffusion of innovations. (4th ed.). New York: Free Press.

[65] Rouibah K., and Hamdy H., (2009). Factors Affecting Information Communication Technologies Usage and Satisfaction: Perspective From Instant Messaging in Kuwait. Journal of Global Information Management.Vol. 17, No 2, pp. 1-29.

[66] Schwartz, S. H., \& Ros, M. (1995). Values in the West: A theoretical and empirical challenge to the individualism-collectivism cultural dimension. World Psychology, 1, 99-122.

[67] Shalom H. Schwartz and Galit Sagie (2000). Value Consensus and Importance: A Cross-National Study. Journal of Cross-Cultural Psychology, Vol. 31 No. 4, July 2000 465-497.

[68] Smotherman, R., and Kooros, S. (2001). Assessing Cultural Differences: Comparing Hofstede's and Trompenaars' Dimensions. Journal of Business Disciplines, Proc. Annual Meeting Academy of Business Disciplines: $20 \mathrm{pp}$.

[69] Sondergaard, M. (1994). Research Note: Hofestede's Consequences: A Study of Reviews, Citations and Replications, Organization Studies, Vol. 15, No. 3:447-456.

[70] Straub, D., K. Loch, R. Evaristo, E. Karahanna and M. Srite (2002). Toward a theory-based measurement of culture. Journal of Global Information Management, Vol, 10, No.1, pp 13-23.

[71] Taegoo (Terry) Kim and Gyehee Lee (2012). A modified and extended Triandis model for the enablersprocess-outcomes relationship in hotel employees' knowledge sharing, The Service Industries Journal, Vol.32:13, pp: 2059-2090.

[72] Taylor, S. and Todd, P. A. (1995). Assessing IT usage: The role of prior experience. MIS Quarterly, 19(4), 561-570.

[73] Thompson S.H. Teo, (2001). Demographic and motivation variables associated with Internet usage activities.Internet Research: Electronic Networking Applications and Policy Volume 11 . Number 2 , pp. $125 \pm 137$.

[74] Thompson, R.K., Higgins, C.A. and Howell, J.M. (1991), “Personal computing: toward a conceptual model of utilization", MIS Quarterly, Vol. 15, pp. 125-43.

[75] Triandis, H. C. (1980). Values, attitudes, and interpersonal behavior. In H. Howe \& M. Page (Eds.), Nebraska symposium on motivation 1979, 195-295. Lincoln, NE: University of Nebraska Press.

[76] Triandis, H. C. (1990). Cross-cultural studies of individualism and collectivism. In J. Berman (Ed.), Nebraska Symposium on Motivation, 1989 (pp. 41-133). Lincoln: University of Nebraska Press.

[78] Veltri, N. F. \& Elgarah, W. (2009). The role of national culture in social networking adoption. In Proceedings of the southern association for information systems conference, March 12-14, 2009, Charleston, SC.

[79] Vijver, F.J.R. van de, \& Leung, K. (1997). Methods and data analysis of comparative research. In J.W. Berry, Y.H. Poortinga, \& J. Pandey (Eds.), Handbook of cross-cultural psychology, 2nd ed. (pp. 257-300). Boston: Allyn \& Bacon. (2nd. ed., vol. 1).

[81] Yong, E. ( 2009). East meets west: How the brain unites us all. New Scientist 2698. Retrieved February $5,2010$.

[82] Yoo, B., Naveen, D. and Lenartowicz, T. (2011). Measuring Hofstese's Five Dimensions of Cultural Values at Individual Level: Development and Validation of CVSCALE. Journal of International Consumer Marketing, 23:3-4, pp 193-210. 